\title{
A Computational Efficiency Principle in action in the processing of recursively embedded PPs in Brazilian Portuguese and in Karajá ${ }^{1}$
}

Marcus Maia ${ }^{a}$

1 Karajá is an agglutinative, pro-drop, head final Brazilian indigenous language of the Macro-Je stock spoken by approximately 3,000 people who live in several villages in Terra Indígena Araguaia and other areas on and around the Bananal Island (TO), in Central Brazil. The Karajá data presented in this paper were collected in the Hawalò village.

\begin{abstract}
This paper presents and discusses two eye-tracking experiments comparing the processing of coordination and embedding of Prepositional Phrases in Brazilian Portuguese (BP) and of Postpositional Phrases in Karajá. Experiment 1 compares the processing of sentences containing Prepositional Phrases which may be self-embedded or conjoined in Brazilian Portuguese. Experiment 2 compares the processing of sentences containing Postpositional Phrases which may be self-embedded or conjoined in Karajá. 20 Brazilian Portuguese (BP) and 20 Karajá subjects had their eye movements monitored as they performed a sentence/picture matching task including sentences in BP and in Karajá, respectively. Based on previous studies reported in Maia et al (to appear), two hypotheses were formulated, both for BP and Karajá, namely, (i) launching the self-embedding of PPS would be more costly to process than launching the conjoining of PPs; (ii) after launching, the subsequent self-embedding of a third PP would be less costly than the previous PP. Results confirmed these predictions and are analyzed in terms of a third factor computational effect learning algorithm.
\end{abstract}

Keywords: Recursion, computational efficiency, Brazilian Portuguese, Karajá

Recebido em 18 de novembro de 2015 Aceito em 25 de janeiro de 2016

aProfessor de Linguística do Departamento de Linguística da Faculdade de Letras da UFRJ, maiamarcus@ gmail.com 


\section{Introduction}

The design of the human language faculty is determined by three factors, according to Chomsky (2005): Universal Grammar (UG), experience, and principles of computational efficiency. UG is the internal innate factor which is part of the genetic endowment of humans; experience provides the triggering effects of linguistic input which interact with the innate principles of UG, and computational efficiency factors are taken to be general principles, which may apply "well beyond language" (CHOMSKY, 2005, p. 9). The present paper intends to demonstrate the operation of a learning algorithm which is analyzed as a third factor principle of computational efficiency in the processing of recursively self-embedded Prepositional Phrases in Brazilian Portuguese and recursively self-embedded Postpositional Phrases in the indigenous Brazilian language Karajá ${ }^{1}$.

Recursion may be characterized as an operation that takes its own output as input (ROEPER, 2010) and has been argued to be unique to the human language faculty (HAUSER; CHOMSKY; FITCH, 2002). In the Minimalist Program (CHOMSKY, 1995), recursion is viewed as an epiphenomenon of Merge:

(1) Merge $(a, b):\{a, b\}$

Constituents may be merged in direct or indirect recursion, as respectively indicated in (2) and (3) below:

(2) $X \rightarrow X($ and $X)$

(3) $\mathrm{X} \rightarrow \mathrm{YZ}$

$$
\mathrm{Z} \rightarrow \mathrm{W}(\mathrm{X})
$$

Direct recursion yields a conjunctive interpretation, whereas indirect recursion requires an extra step in the derivation and results in a structure with self-embedding. The Brazilian Portuguese and Karajá following examples 
illustrate conjoined and recursively embedded Prepositional and Postpositional Phrases:

(4) Tem jacaré na esteira, na pedra e na areia.

"There is (an) alligator on the mat, on the rock and on the sand".

(5) Orera byre-tyreki ijõdire, ijõ myna-tyreki, ijõ ynyratyreki alligator mat-on there is, another rock-on, another sand-on "There is (an) alligator on the mat, on the rock and on the sand".

(6) Tem jacaré na esteira na pedra na areia.

"There is (an) alligator on the mat on the rock on the sand".

(7) Orera ijõdire byre-tyreki myna-tyreki ynyra-tyreki alligator there is mat-on rock-on sand-on

"There is (an) alligator on the mat on the rock on the sand"

2 This study presented results of two Eventrelated Brain Potential (EEG-ERP) experiments, comparing the electrophysiological responses in the reading of sentences containing either conjoined or embedded PPs in PB and in Karajá. The results seem to point to a progressive facilitation at each PP within the coordination mode which, in contrast with the results obtained for PP embedding, yielded earlier N400. Nevertheless, there was also a progressive facilitation going from the constructions with one embedded PP, to two PPs and three PPs. These effects are interpreted by the authors as a third factor computational efficiency process.

Notice that coordination is indicated in BP by a comma between the first PP and the second PP and by the additive conjunction $e$ "and" (example 4), whereas embedding displays no pauses or conjunctions between the PPs (example 6). In Karajá, coordination is indicated by the ijõ "other" operator both between the first and the second PPs and between the second and the third PPs (example 5), whilst embedding displays no conjunctions or pauses between PPs (example 7), as it is the case in BP.

Based on previous neurophysiological evidence presented in Maia et al. (to appear) ${ }^{2}$, it is hypothesized in the current paper that (i) conjoined PP constructions such as (4) in BP and (5) in Karajá are easier to process than self-embedded $\mathrm{PP}$ constructions such as (6) in BP and (7) in Karajá, which require an extra step in their derivation; (ii) the difficulty encountered as soon as self-embedding is detected in the second PP is lessened once the process is established and does not pose any extra effort for the processing system. The 
first prediction can be understood in terms of the on-line implementation of grammatical conditions. Following Marr (1982) the grammatical computational level provides the input to be implemented by algorithms of real-time sentence processing. Thus, we claim that the more complex derivation characteristic of indirect recursion vis-à-vis direct recursion can be experimentally captured in terms of processing cost. In contrast, the second prediction is claimed to be a third factor, that is to say, an efficiency algorithm which is restricted to processing. In this respect, we follow the proposal in Trotkze, Bader \& Frazier (2013) that "properties of performance systems can play an important role within the biolinguistic perspective on language by providing third-factor explanations for crucial design features of human language" (TROTKE; BADER; FRAZIER, 2013, p. 28).

The article unfolds as follows. In Section 2, an eye-tracking experiment testing BP subjects is presented. In Section 3, an eye-tracking experiment testing Karajá subjects is presented. In Section 4, the conclusions of the study are presented.

\section{The BP eye-tracking study}

This study monitored the eye gaze of subjects as they performed a sentence/picture matching task. Subjects were asked to decide as fast as possible whether a sentence they read on the screen, as they simultaneously looked at a picture, was compatible with the picture they were seeing. As subjects performed this task their eye movements were monitored through a TOBII TX300Hz eye- tracker.

The independent variables were (1) number of PP in the constructions $(1,2,3)$ and (2) type of structure (embedding or coordination). The dependent variables were Total Fixation duration in each PP area (on-line measure) and the decision accuracy rates in the sentence/picture test (off- line measure).

Design and Materials: 12 sets of experimental items (1 conjoined +1 embedded), distributed in two versions in a Latin square design +24 distracting fillers in each version. Sentences were written in Monaco 28pt Font (True Type). An example of the conjoined condition is given in Fig. 1 and an example of the embedded condition is given in Fig. 2: 
Figure 1 - Example of a BP conjoined PP condition

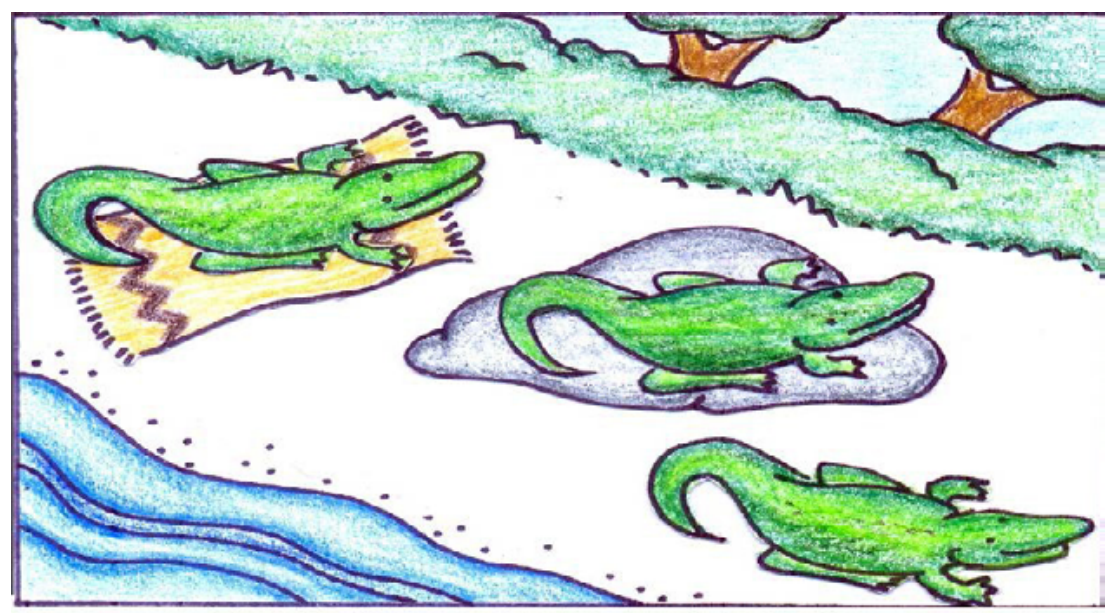

Tem jacaré na esteira e na pedra e na areia

Figure 2 - Example of a BP embedded PP condition

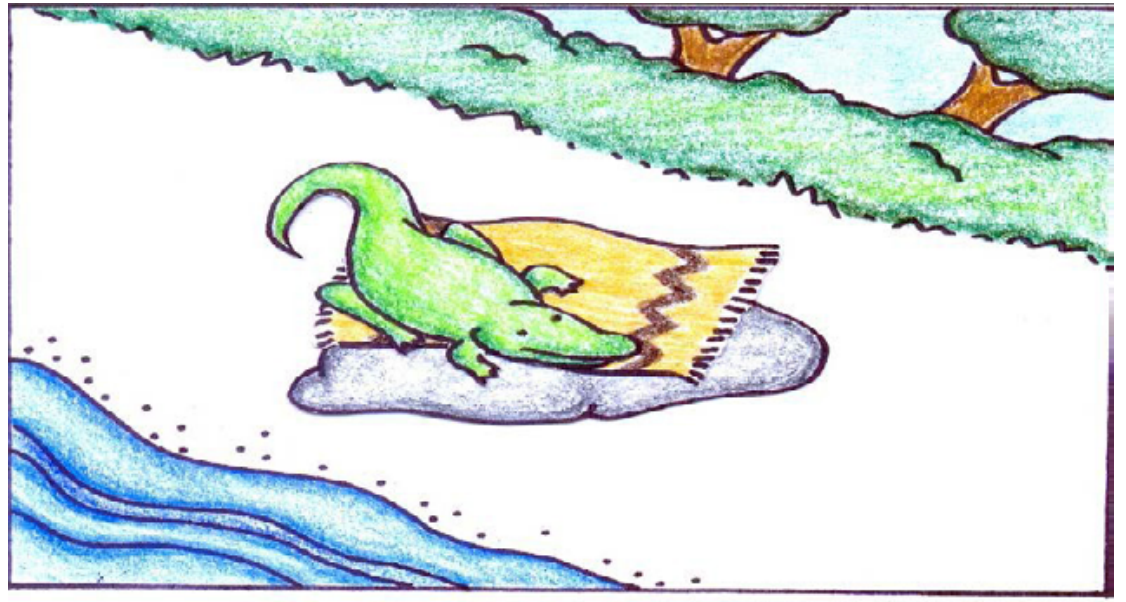

Tem jacaré na esteira na pedra na areia

Participants: 20 UFRJ students averaging 21 years old.

Procedures: Subjects were told that they would be presented with an image of a scene which would remain on 
the screen for two seconds, after which a sentence would appear in the bottom of the screen. Subjects were instructed to read the sentence and press a button as fast as they would be ready to judge whether the image and the sentence were compatible. As they pressed a button, another screen would appear with the words SIM "yes" and NÃO "no". Subjects should, then, look at the right answer to record their answers. Fig. 3 exemplifies this screen, which would disappear after two seconds, being replaced by the next image.

Figure 3 - Eye gazes were recorded as subjects looked at the sentence/picture matching answer after each trial

\section{S IM}

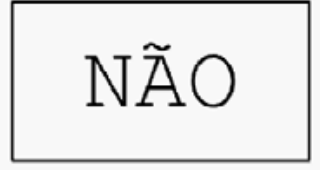

After a calibration session, during which subjects should follow a red ball moving on the screen, three practice items would be presented to ensure the correct comprehension of the task by the subjects. After this practice, subjects were told to press the space bar to start the experiment as soon as the experimenter left the room.

\section{Results}

Average fixation durations in each PP area both in the conjoined and in the embedded conditions were computed, yielding the results presented in Graph 1 and in Table 1: 
Graph 1 - Average Fixation Durations in PP areas in Recursively embedded and Conjoined conditions

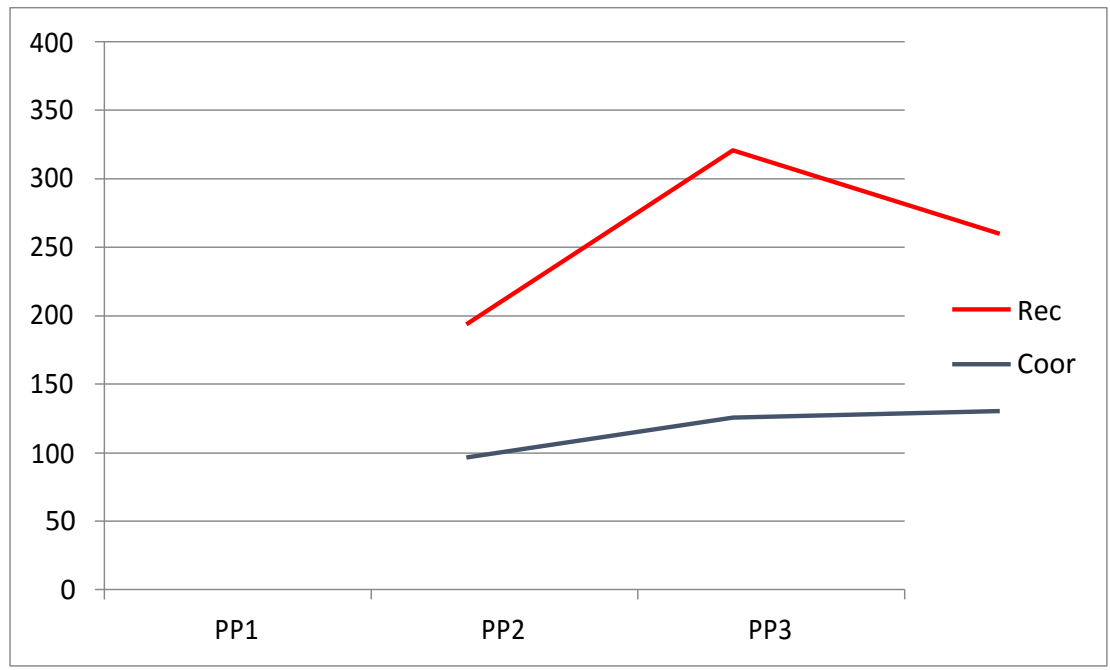

Table 1 - Average Fixation Durations in PP areas in Recursively embedded and Conjoined conditions

\begin{tabular}{lccc}
\hline & PP1 & PP2 & PP3 \\
\hline Rec & 246 & 373 & 312 \\
\hline Coord & 244 & 273 & 278 \\
\hline
\end{tabular}

A 2 Within subject Factors ANOVA was performed revealing a highly significant main effect of Number of PPs $\left(\mathrm{F}(2,238)=130 \mathrm{p}<0.000001^{* * *}\right)$, as well as a highly significant effect of Syntax of PPs $\left(F(1,119)=171 \mathrm{p}<0.000001^{* * *}\right)$. There was also highly significant interaction between the two factors $\left(\mathrm{F}(2,238)=49.6 \mathrm{p}<0.000001^{* * *}\right)$. The relevant pairwise $\mathrm{t}$-test comparisons were also performed. Notice that there is no significant difference in the fixation times of PP1 between the two conditions ([PP1_Rec]vs[PP1_Coord] $t(119)=0.49 \mathrm{p}<$ 0.6227 n.s.). However, there is a clear significant difference when the second PP is compared across the syntactic condition ([PP2_Rec]vs[PP2_Coord] $t(119)=12.81 \mathrm{p}<0.0001^{* *}$ ). Note that the difference is in the expected direction, that is, 
the recursively embedded second PP (e.g. Tem jacaré na pedra na esteira na areia - There is an alligator on the rock on the mat on the sand) requires longer fixation durations than its conjoined counterpart (e.g. Tem jacaré na pedra e na esteira e na areia - There is an alligator on the rock and on the mat and on the sand). This difference between the embedding and the conjoining processes is also observed in the third PP $\left(\left[P P 3 \_R e c\right] v s\left[P P 3 \_C o o r d\right] t(119)=4.89 p<0.0001\right)$, in the same direction, that is, the embedded PP requires average fixation durations which are significantly longer than the average durations obtained for the conjoined PP. However, crucially, note that, even though there is a significant difference between the average fixation times of the second embedded PP and the third embedded PP (PP2_Rec]vs[PP3_Rec] $t(119)=7.68$ $p<0.0001)$, there is no significant difference between the average fixation times of the second conjoined PP and the third conjoined PP ([PP2_Coord]vs[PP3_Coord $] \mathfrak{t}(119)=0.53$ $\mathrm{p}<0.5987)$, which remain at the same level.

Decision accuracy rates were equally high (>95\%) in all experimental conditions and fillers, without any significant difference to report. Even though these off-line results are not interesting in terms of the independent variables observed, the high rates of accurate decisions in the sentence/picture matching task adds to the general reliability of the experiment, crucially attesting to the importance and to the relevance of the on-line measure in order to assess all factors in the design.

\section{Discussion}

The on-line results of the experiment support the EEG findings of Maia et al. (to appear): when the processor encounters the second PP there is a significant rise in average fixation times if the syntactic process is self-embedding of the PP in comparison with the PP-conjoining process. This is analyzed as an indication of the difficulty inherent to the embedding process, which would not be the default process, if compared to the conjoining process, which seems to require fewer fixations and can be, therefore, interpreted as being easier to process. Fig. 4 presents a typical example of the fixation pattern obtained in the conjoining process and Fig. 5 illustrates the typical fixation pattern in the embedding process. The heat maps identify in green the areas with less fixation durations, in yellow, the areas 
with more fixation duration and, in red, the areas with the most fixation durations.

Figure 4 - Heat map of fixation durations in a PP conjoining condition

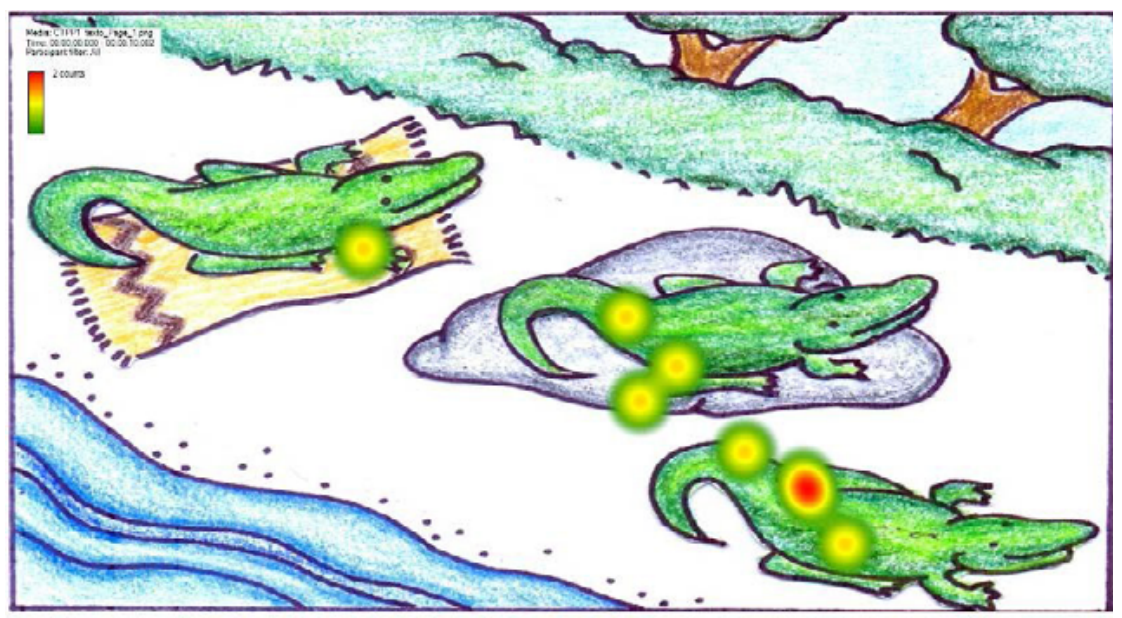

Tem jaca@na e Qeira e $7 a \mathrm{O}$ e $\mathrm{O}$ areia

Figure 5 - Heat map of Fixation Durations in a PP embedding condition

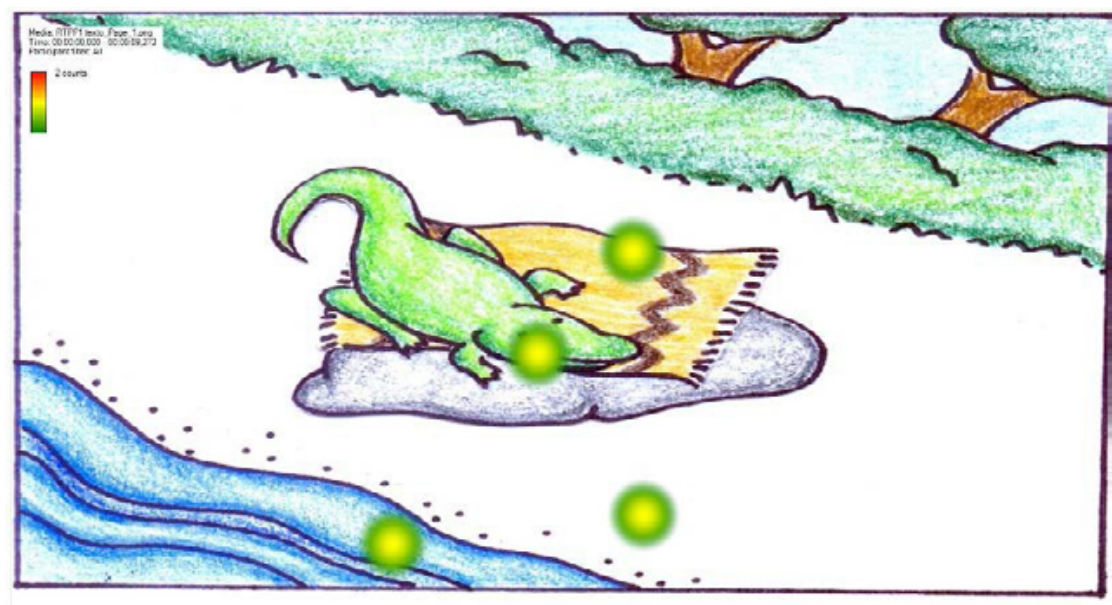

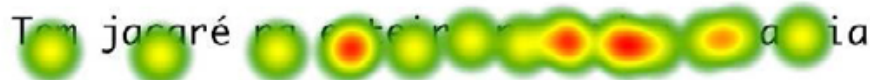


It may be noticed that fixations in the reading of the PP conjoining condition illustrated in Fig. 4 tend to be more evenly distributed among the three PPs than in the reading of the PP embedding condition in Fig. 5, in which the area of the second embedded PP clearly receives higher fixation durations than the other two PP areas, including the third PP, indicating some form of habituation ${ }^{3}$ to the embedding process.

The fact that there is habituation to recursively embedded PP processing, however, indicated by a significant fall in processing difficulty for embedding in the third PP, seems to allow for the interpretation that there is a learning algorithm at work - recursion is not the default and even though it is costly to be launched, once the process is established it falls back to decreased levels of difficulty and does not pose any extra significant effort to the system. Of course, it could be argued that the embedding of a fourth recursive PP would probably raise processing times, taking into account short term memory limitations. However, the experiment seems to have captured an interesting effect: embedding is harder to engage than conjoining, but seems to be subject to a third factor computational efficiency learning algorithm which lowers its cost once the process has been launched. Conjoining, on the other hand, being the default process, remain at the same levels of difficulty, as indicated by comparisons between the second and the third conjoined PPs, even though it is predictable that memory limitations would probably also apply if the process is continued.

\section{The Karajá eye-tracking study}

An equivalent eye-tracking experiment was designed and run with Karajá subjects in the Karajá indigenous village of Hawalò, in an experimental field trip, in January, 2015. As in the BP experiment, the eye gaze of Karajá subjects was monitored as they performed a sentence/picture matching task. The Karajá subjects were required to decide as fast as

3 Rankin et a 1 (2009) thoroughly review the concept of habituation, from its characterization as the simplest form of learning to the specification of nine of its properties. possible whether a sentence they read on the screen, as they simultaneously looked at a picture, was compatible with the picture they were seeing. As subjects performed this task, their eye movements were monitored through a TOBII TX300Hz eye-tracker. 
The Karajá study had a similar design as the experiment run with the $\mathrm{BP}$ subjects. The independent variables were (1) number of PP in the constructions $(1,2,3)$ and (2) type of structure (embedding or coordination). The dependent variables were Total Fixation duration in each PP area (online measure) and the decision accuracy rates in the sentence/ picture test (off-line measure).

Design and Materials: 12 sets of experimental items (1 conjoined +1 embedded), distributed in two versions in a Latin square design +24 distracting fillers in each version. Sentences were written in Monaco 28pt Font (True Type)

An example of the conjoined condition is given in Fig. 6 and an example of the embedded condition is given in Fig. 7:

Figure 6 - Example of a Karajá conjoined PP condition

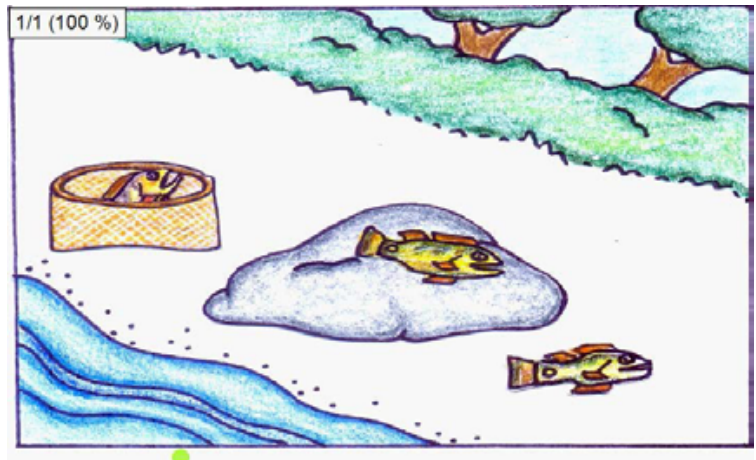

Utura weriri-roki ijõdire, ijõ myna-tyreki, ijõ ynyra-tyreki

Figure 7 - Example of a Karajá embedded PP condition

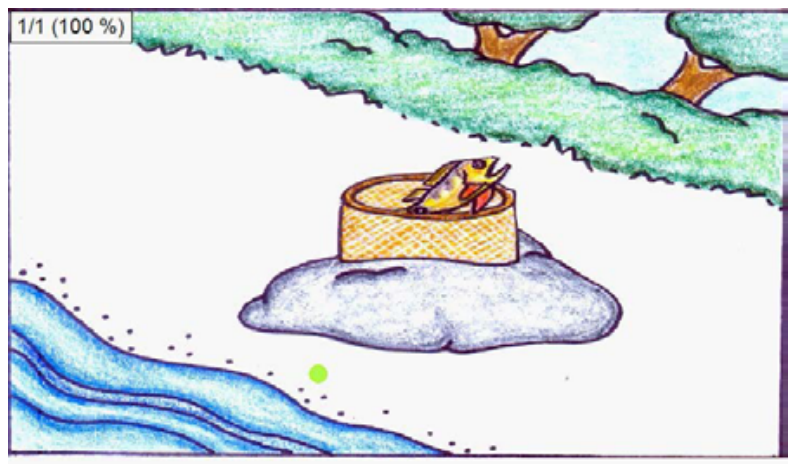

Utura ijōdire weriri-roki myna-tyreki ynyra-tyreki 
Eye gazes were recorded as subjects looked at the sentence/ picture matching answer after each trial. After a calibration session, during which subjects should follow a red ball moving on the screen, three practice items would be presented to ensure the correct comprehension of the task by the subjects. After this practice, subjects were told to press the space bar to start the experiment as soon as the experimenter left the room.

Participants: 20 Karajá subjects averaging 30 years old. Subjects were all native speakers of Karajá, having acquired the Karajá language as their first language in the Hawalò village (TO), speaking Portuguese as a second language.

Procedures: Subjects were informed that they would see an image of a scene which would remain on the screen for two seconds, after which a sentence would appear in the bottom of the screen. Subjects were asked to read the sentence and press a button as fast as they would be ready to judge whether the image and the sentence were compatible. As they pressed a button, another screen would appear with the words KOHE "yes" and KÕRE "no". Subjects should, then, look at the right answer to record their answers.

\section{Results}

Average fixation durations in each PP area both in the conjoined and in the embedded conditions were computed, yielding the results presented in Graph 2 and in Table 2:

Graph 2 - Average Fixation Durations in PP areas in Recursively embedded and Conjoined conditions

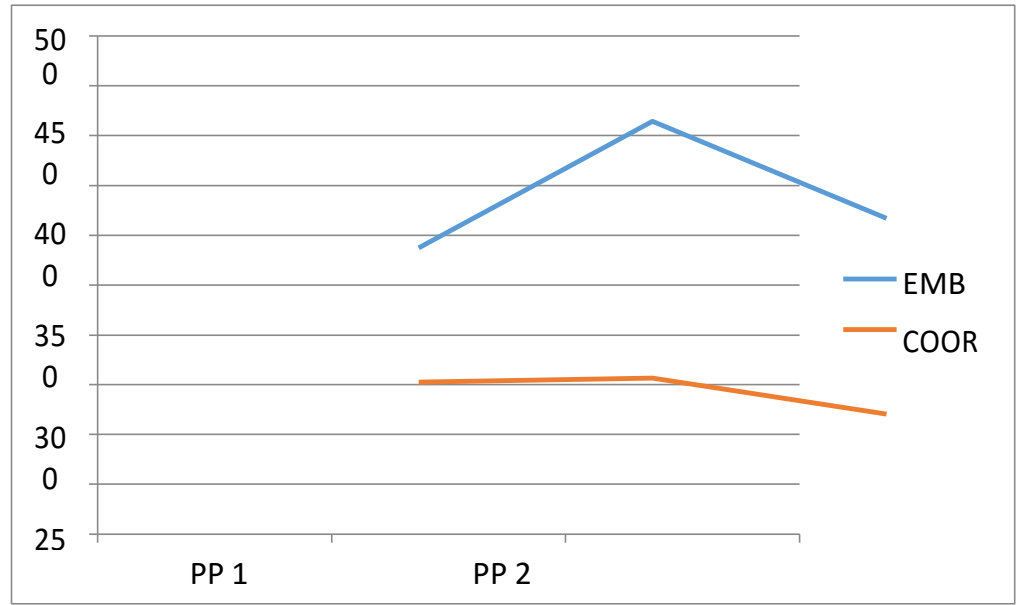


Table 2 - Average Fixation Durations in PP areas in Recursively embedded and Conjoined conditions

\begin{tabular}{lccc}
\hline & PP1 & PP2 & PP3 \\
\hline Emb & 346 & 473 & 376 \\
\hline Coord & 340 & 344 & 308 \\
\hline
\end{tabular}

As in the BP experiment, a 2 Within subject Factors ANOVA was performed revealing a highly significant main effect of Number of PPs $(\mathrm{F}(2,238)=21.2 \mathrm{p}<0.000019 * * *)$, as well as a significant effect of Syntax of PPs $(\mathrm{F}(1,119)=24.2$ $\left.\mathrm{p}<0.000825^{* *}\right)$. There was also a significant interaction between the two factors $\left(\mathrm{F}(2,238)=12.9 \mathrm{p}<0.000334{ }^{* *}\right)$. The relevant pairwise t-test comparisons were also performed. Notice that there is no significant difference in the fixation times of PP1 between the two conditions ([PP1_Rec]vs[PP1_Coord] $t(119)=$ $0.19 p<0.9227$ n.s.), as also obtained in the BP experiment. On the other hand, notice, crucially, that the second PPs fixation times do differ significantly when compared across the two syntactic conditions ([PP2_ Rec]vs[PP2_Coord $] \mathfrak{t}(119)=5.78$ $\mathrm{p}<0.0003)$. The difference is in the expected direction, that is, the recursively embedded second PP (e.g. Orera ijõdire byretyreki myna-tyreki ynyra-tyreki - There is an alligator on the rock on the mat on the sand) requires longer fixation durations than its conjoined counterpart (e.g. Orera byre-tyreki ijõdire, ijõ myna-tyreki, ijõ ynyra-tyreki - There is an alligator on the rock and on the mat and on the sand). This difference between the embedding and the conjoining processes is also observed in the third PP ([PP3_Rec]vs[PP3_Coord] $t(119)=3.17 \mathrm{p}<0.0114)$, in the same direction, that is, the embedded PP requires average fixation durations which are significantly longer than the average durations obtained for the conjoined PP. However, crucially, note that, as obtained in the BP experiment, there is for Karajá also a significant difference between the average fixation times of the second embedded PP and the third 
embedded PP (PP2_Rec]vs[PP3_Rec] $\mathrm{t}(119)=4.92 \mathrm{p}<0.0008)$. Unlike the BP eye-tracking experiment, though, there is a significant difference between the average fixation times of the second conjoined PP and the third conjoined PP ([PP2_Coord] $\mathrm{vs}[\mathrm{PP} 3$ Coord] $\mathrm{t}(119)=4.56 \mathrm{p}<0.0014$. Despite this difference between the $\mathrm{BP}$ and the Karajá tests, both experiments indicate higher cost for embedding PPs than for conjoining PPs. Even though Karajá fixation times are overall higher than the times obtained for the BP subjects, the same effect of acommodation to the third recursively embbeded PP vis-à-vis the second embedded PP seems to have been captured.

Decision accuracy rates were equally high (>88\%) in all experimental conditions and fillers, without any significant difference to report. Even though these off-line results are not interesting in terms of the independent variables observed, the high rates of accurate decisions in the sentence/picture matching task add to the general reliability of the experiment, crucially attesting to the importance and to the relevance of the on-line measure in order to assess all factors in the design.

\section{Discussion}

The on-line results of the Karajá eye-tracking experiment are basically in line with the BP eye-tracking experiment reported in section II of this article. When the processor encounters the second PP there is a significant increase in the average fixation times if the syntactic process is selfembedding of the PP in contrast with the PP-conjoining process, which requires less fixations. Fig. 8 provides a heat map of the fixation duration pattern in the reading of a PP conjoining sentence, and Fig. 9 exemplifies the fixation duration pattern in the reading of PP embedding sentence. Notice in Fig. 8 that fixations are more evenly distributed among the three PPs, in contrast with the fixation duration pattern obtained for the embedding process in Fig. 9, in which the second embedded PP receives the highest durations. 
Figure 8 - Fixation duration patterns in the visualization of a Karajá PP conjoining condition

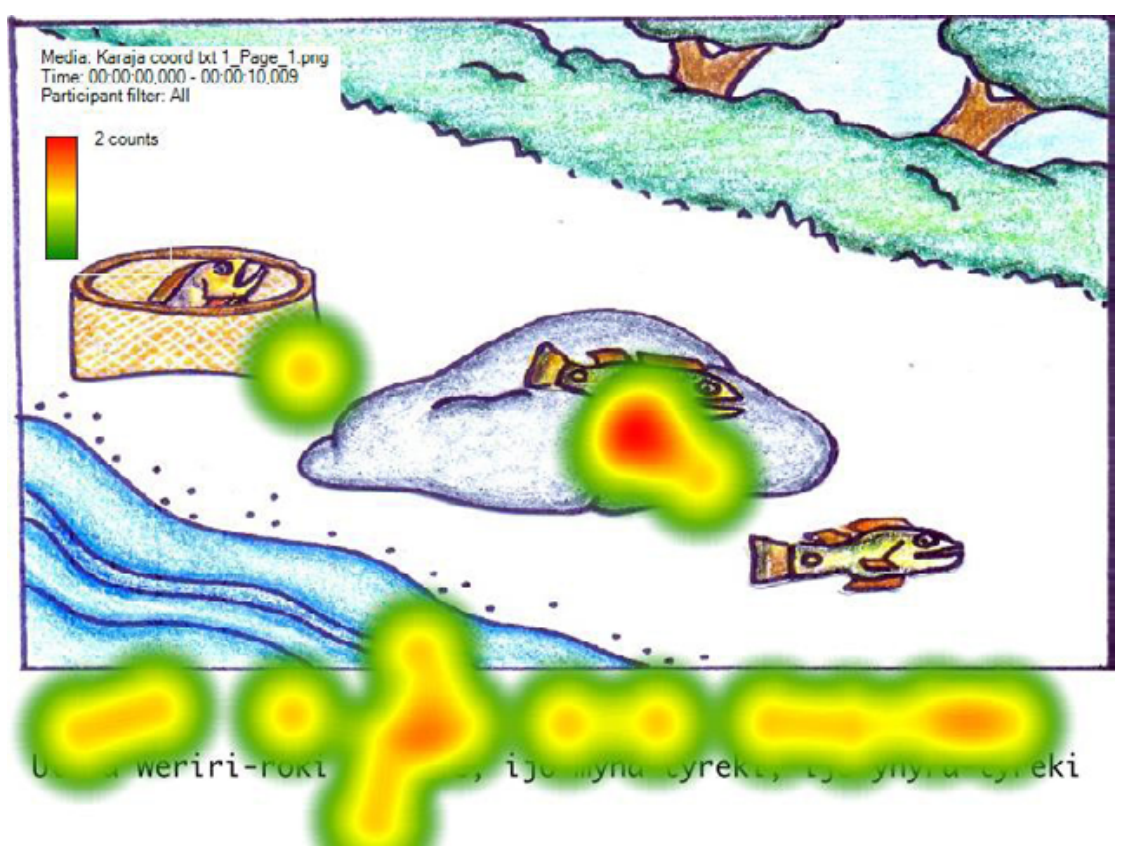

Figure 9 - Fixation duration patterns in the visualization of a Karajá PP embedding condition

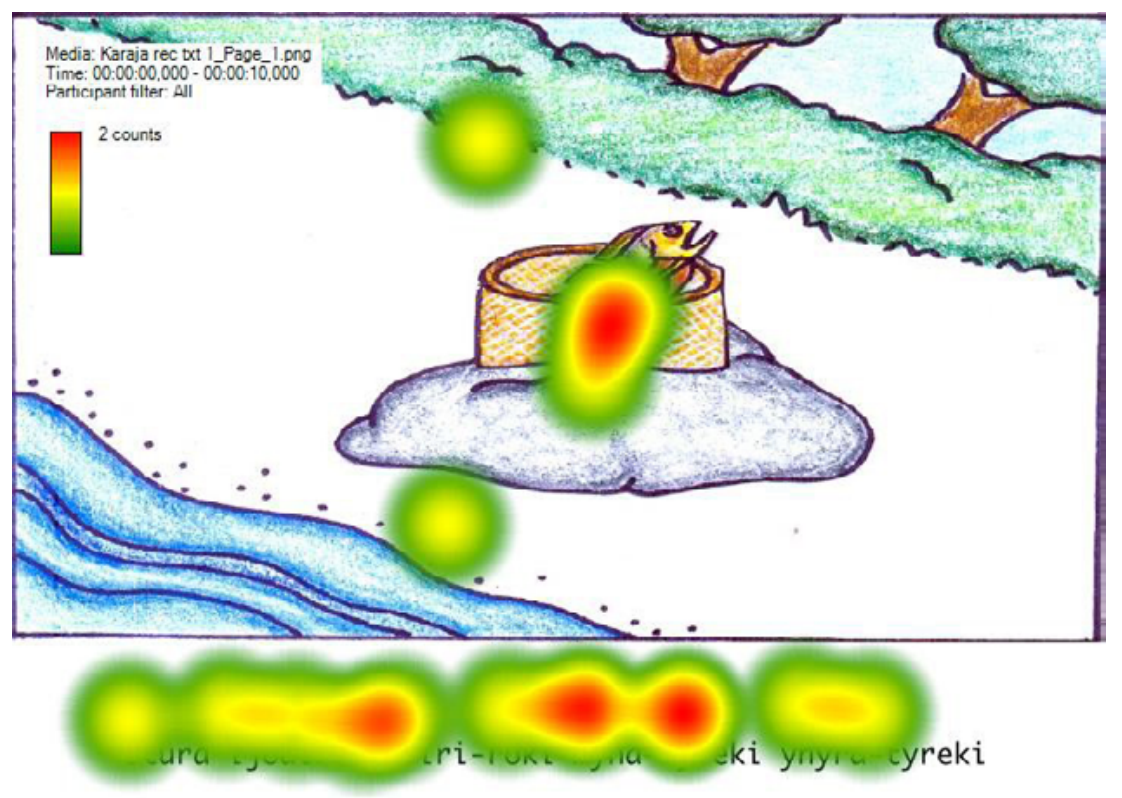


Even though overall fixation times are higher for all conditions in Karajá in comparison to BP, the Karajá data basically support the analysis that there is an inherent difficulty in the launching of the embedding process which contrast with the launching of the coordination process, the default process. The existence of a process of habituation to recursively embedded PP processing is also verified in Karajá, as there is a significant fall in processing difficulty for embedding in the third PP, even though in Karajá there is also a significant fall in fixation times between the second and the third conjoined PPs, what might indicate habituation also in the coordination process ${ }^{4}$. Anyway, these patterns allow for the interpretation that there is a learning algorithm at work once the syntactic process is established it falls back to shorter levels of difficulty and does not pose any extra significant effort to the system. Of course, it could be argued that the embedding (or even the conjoining) of a fourth recursive PP would probably raise processing times, taking into account short term memory limitations.

${ }^{4}$ The significant fall in reading times for the third PP in conjunction in Karajá might be taken as an additional piece of evidence in favor of our third factor analysis, since the learning algorithm we propose would not be restricted to self-embedding, instantiating in coordination as well. An anonymous reviewer of Revista Gragoatá suggests that the fact that the habituation effect occurs in Karajá, but not in BP could be due to the nature of the conjoining operator in Karajá, which meaning "other/ another", might involve pragmatic processing. As the testing of such an interesting hypothesis would require specific experimentation, we can only acknowledge here this compelling idea, which may be object of a future study.

\section{Conclusions}

The two experiments reported in this article seem to have captured an interesting effect: embedding is harder to engage than conjoining, but seems to be subject to a third factor computation efficiency learning algorithm which lowers its cost once the process has been launched. In the Karajá experiment even though conjoining is shown to be significantly easier to process than embedding in PP2 and PP3, there is, however, a facilitation for the third PP both in the embedding and in the conjoining conditions.

Finally, as already noted in Maia et al. (to appear), it should be clear that we are not arguing in the present paper either that recursion could be reduced to a processing effect since such a conclusion could not be granted by the findings in the two eye-tracking experiments conducted: in both tests, the coordination results yielded faster fixation durations than those of recursively embedded PPs, even though in the offline measures both processes did not differ in terms of their acceptability rates which were basically the same. We assume 
that both the operations of direct merge and indirect merge that are respectively necessary to coordinate and to embed PPs are not extra-grammatical, but primitive narrow faculty computations. However, the subtlety of the on-line eye-tracking results suggests that (i) launching embedding is harder than launching coordination, both in BP and in Karajá; (ii) syntactic facilitation does appear in the subsequent embedding in the BP experiment and both in the subsequent embedding and conjoining in the Karajá experiment. We interpreted this facilitation as a performance or third factor phenomenon: once engaged in the syntactic algorithm, subsequent mergers are facilitated.

\section{REFERENCES}

CHOMSKY, Noam. Three Factors in Language Design. Linguistic Inquiry v. 36, p. 1-22, 2005.

CHOMSKY, Noam. The Minimalist Program. Cambridge, Mass.: The MIT Press, 1995.

RANKIN C. H., ABRAMS T., BARRY R. J., BHATNAGAR S., CLAYTON D. F., COLOMBO J. Habituation revisited: an updated and revised description of the behavioral characteristics of habituation. In: Neurobiol Learn Mem. 2009 Sep;92(2):135-8. doi: 10.1016/j.nlm.2008.09.012. Epub 2008 Nov 6.

HAUSER, M D.; CHOMSKY, N; FITCH, W, T. The Faculty of Language: What Is It, Who Has It, and How Did It Evolve? In: Science Compass, v. 298. p. 1569-1579, nov. 2002. Available at: <http://www.chomsky.info/articles/20021122.> MAIA, M., FRANÇA, A.I., LAGE, A., OLIVEIRA, C., GESUALDI, A., GOMES, J., SOTO, M. (to appear). The processing of $P P$ embedding and coordination in Karajo and in Brazilian Portuguese. Manuscript. UFRJ.

MARR, David. Vision: A computational investigation into the human representation and processing of visual information. Cambridge, MA: MIT Press, 1982.

ROEPER, T. Recursion: what is innate, why it needs a trigger, where it belongs in cross- linguistic work and How it fits into the Mind. In: Aniela França \& Marcus Maia (orgs). Papers in Psycholinguistics. Rio de Janeiro: Imprinta, p. 38-60, 2010. 
TROTZKE, A. BADER, M. \& FRAZIER, L. Third Factors and the Performance Interface in Language Design. In: Biolinguistics 7: 001-034, 2013 ISSN 1450-3417. Available at:< http://www. biolinguistics.eu>

\section{Resumo}

Um Princípio de Eficiência Computacional em ação no processamento de SPs encaixados e coordenados em Português brasileiro e em Karajá

Este artigo apresenta e discute dois experimentos psicolinguísticos de rastreamento ocular comparando o processamento da coordenação e do encaixe de Sintagmas Preposicionais (SP), em Português Brasileiro $(P B)$ e de Sintagmas Posposicionais (SP) em Karajá. O experimento 1 comparou o processamento de frases contendo Sintagmas Preposicionais que podem estar coordenados ou encaixados recursivamente em Português do Brasil. O experimento 2 comparou o processamento de Sintagmas Posposicionais que poderiam estar recursivamente encaixados ou coordenados em Karajá. 20 sujeitos falantes de Português Brasileiro (PB) e 20 sujeitos falantes de Karajá tiveram seus movimentos oculares monitorados enquanto realizavam uma tarefa de julgamento de correspondência entre frase e imagem. Com base em estudos anteriores relatados em Maia et alii (a aparecer), duas hipóteses foram formuladas, tanto para o BP quanto para o Karajá, a saber, (i) o lançamento do processo de encaixe de SPs seria mais caro para processar do que o lançamento do processo de coordenação de SPs; (ii) após o lançamento, o terceiro SP seria menos custoso do que o SP anterior. Os resultados confirmaram essas previsões e são analisados em termos de um algoritmo de aprendizagem, funcionando como um efeito computacional de terceiro fator.

Palavras-chave: Recursividade, eficiência computacional, Português brasileiro, Karajá 